\title{
Brazilian owners perception of the body condition score of dogs and cats
}

\author{
Fabio Alves Teixeira', Mariana Ramos Queiroz', Patrícia Massae Oba², Rodrigo Fernando Gomes Olivindo', \\ Mariane Ceschin Ernandes ${ }^{1}$, Caio Nogueira Duarte ${ }^{1}$, Mariana Fragoso Rentas ${ }^{1}$ and Marcio Antonio Brunetto ${ }^{1 *}$
}

\begin{abstract}
Background: The knowledge of how owners view the body condition of their animals is an important factor for the success of the prevention/treatment of obesity and the engagement/adherence to nutritional interventions, which are fundamental to improve the animal prognosis. For this reason, the objective of this study was to evaluate the perception of the owners regarding the body condition score of their animals, compare the perception between cat vs. dog owners, and owners from the countryside vs. metropolitan region of São Paulo State in Brazil.

Results: 601 dogs and 110 cats were included in this study. There was no significant difference in body condition score assigned by owners by species. Owners of dogs and cats classified by the veterinarian as ideal, overweight, and obese who disagree with body condition score assigned by veterinarian mainly underestimate the body condition score of their animals, while lean dogs' owners overestimate it. Countryside dog owners had a higher rate of disagreement with the veterinarian and more often underestimate the body condition score than owners from the metropolitan region. The owners of lean cats have the same judgments with veterinarians.
\end{abstract}

Conclusions: Owners of dogs and cats have difficulty assessing the body condition score, especially owners from countryside.

Keywords: canine, feline, obesity, nutritional assessment, body composition, nutritional tool

\section{Background}

The body condition score (BCS) is an important tool to determine the nutritional status of dogs and cats in clinical cases $[1,2]$. Nowadays, obesity is the most commonly diagnosed nutritional disorder in cats and dogs and its prevalence is increasing in the last few years [3, 4]. BCS is the primary diagnostic tool for obesity [5]. Helping pet owners identify when their animals are getting overweight is essential to prevent obesity and avoid the consequences that this disorder can generate such as

\footnotetext{
*Correspondence: mabrunetto@usp.br

This study was presented, in part, at the 2015 AAVN Symposium, June 3, 2015, Indianapolis, IN.

'Department of Animal Nutrition and Production, School of Veterinary Medicine and Animal Science, University of São Paulo, Av. Duque de Caxias Norte, 255, Pirassununga, SP, São Paulo, Brazil

Full list of author information is available at the end of the article
}

insulin resistance; diabetes mellitus; higher levels of inflammatory cytokines; hyperlipidemia; possible relation to cardiac, respiratory, skin, pancreatic and renal disease; hepatic lipidosis; osteoarthritis; negative impact on the quality of life and life span [6-16].

Besides, tracking the BCS assists in the monitoring of cardiac, renal, oncological, and endocrine diseases; as well as to determine the optimal time to initiate the intensive nutritional support for the hospitalized small animal patient [8, 17-23]. Furthermore, a stable BCS is associated with shorter hospitalization time and a higher hospital discharge rate, which is directly related to fewer costs to the owner [24-27].

The validated BCS for cats [28] and dogs [29] is a subjective semi-quantitative method, ranging from very thin $(B S C=1)$ to severely obese $(B S C=9)$. It involves an assessment of the visual and palpable characteristics of 
body fat at different body parts [1]. Studies conducted in other countries have shown that the owners tend to underestimate the BCS of their animals, especially obese animals [30-33]. In Brazil, studies only focus on the evaluation of overweight dogs were performed [34, 35]. For cats, high to moderate agreement between veterinary and owners perception of BCS, but among owners who incorrectly estimated the BCS of their cats, there is more underestimate, as found in the literature [36-40]. Only one study was found about Brazilian cat owners' misperception of cat's BCS, and it was conducted in a Brazilian countryside region [37]. Thus, there is no information regarding the perception of Brazilian owners regarding the BCS of their dogs and cats, as well as there is no comparison between the perceptions of dogs vs. cats owners.

Therefore, this study aimed to compare the perception of dogs and cats owners regarding the BCS of their animals; additionally, among owners who disagree with the $\mathrm{BCS}$ assigned by the veterinarian, if the propensity of the owners is to underestimate or overestimate the BCS of their animal; and to compare whether the BCS perception of dog and cat owners change according to them where they live (metropolitan region vs. countryside of São Paulo State, Brazil).

\section{Results}

The study included 601 dogs and 110 cats. The distribution of animals by species, location, sex, most prevalent breeds and age is shown in Table 1 . At metropolitan region, 39 canine breeds were included at study: Mongrel (23.9\%), Poodle (16.4\%), Labrador Retriever (10.3\%), Spaniel Cocker (4.9\%), Dachshund (4.9\%), Yorkshire Terrier (4.2\%), Lhasa Apso (3.4\%), Pinscher (3.4\%), Schnauzer (2.9\%), Maltese (2.7\%), Shih Tzu (2.4\%), Beagle $(2.1 \%)$, Bichon Frise (2.1\%), Pomeranian (2.1\%), Golden Retriever (1.9\%), Pug (1.9\%), Pit Bull (1.3\%), English Bulldog (1.1\%), Boxer (0.8\%), Sharpei (0.8\%), Akita
(0.5\%), Brazilian Terrier (0.5\%), Germany Shepard (0.5\%), Weimaraner (0.5\%), Belgian Malinois (0.3\%), Bernese (0.3\%), Brazilian Mastiff (0.3\%), Border Collie (0.3\%), Bull Terrier (0.3\%), Chow Chow (0.3\%), French Mastiff (0.3\%), English Setter (0.3\%), Germany Pointer (0.3\%), Mastiff $(0.3 \%)$, Neapolitan Mastiff (0.3\%), Rhodesian $(0.3 \%)$, Rottweiler $(0.3 \%)$, Scottish Terrier $(0.3 \%)$ and West Highland White Terrier (0.3\%). The feline breeds were: Mongrel (82.7\%), Siamese (11.1\%), Persian (5.0\%) and Abyssinian (1.2\%). At countryside, the canine breeds were: Mongrel (50.0\%), Poodle (4.9\%), Dachshund (4.5\%), Shih Tzu (4.5\%), Yorkshire Terrier (4.0\%), Lhasa Apso (3.6\%), American Pit Bull (3.2\%), Pinscher (3.2\%), Border Collie (2.7\%), Golden Retriever (2.7\%), Labrador Retriever (2.7\%), Beagle (1.8\%), Pug (1.8\%), Rottweiler (1.4\%), Akita (0.9\%), Boxer (0.9\%), Brazilian Terrier (0.9\%), Cocker (0.9\%), Maltese (0.9\%), Schnauzer $(0.9 \%)$, Australian Cattle Dog (0.4\%), Bernese (0.4\%), Bichon Frise (0.4\%), Chihuahua (0.4\%), Chow Chow (0.4\%), Germany Shepherd (0.4\%), Pomeranian (0.4\%), Siberian Husky $(0.4 \%)$ and West Highland White Terrier $(0.4 \%)$. At this region, feline breeds were Mongrel (96.6\%) and Persian (3.4\%).

The proportions of underestimation, agreement, and overestimation of BCS by owners of dogs and cats, separated by owners residing in the metropolitan and countryside region, and the degree of agreement by the linear weighted kappa test are available in Table 2.

When data were analyzed considering all BCS ranges (Table 2), in general, and in the metropolitan region the dogs and cats owners showed a high degree of agreement between the body condition score classified by owners (BCSo) vs. body condition score classified by veterinarian $(\mathrm{BCSv})(\mathrm{K}=0.64$ to $0.69 ; p<0.01)$ and in the countryside the agreement was considered as moderate $(\kappa=0.54$ and $0.58 ; p<0.01)$. However, when evaluating the distribution of disagreement with the BCSv it is possible to notice that, regardless of the region, the dog

Table 1 Description of the metropolitan and countryside region animals included in the study

\begin{tabular}{|c|c|c|c|c|}
\hline & \multicolumn{2}{|l|}{ Metropolitan } & \multicolumn{2}{|l|}{ Countryside } \\
\hline & Dogs & Cats & Dogs & Cats \\
\hline Number of animals & 377 & 81 & 224 & 29 \\
\hline $\operatorname{Sex}(M \% / F \%)$ & $43.2 / 56.8$ & $40.7 / 59.3$ & $36.6 / 63.4$ & $24.1 / 75.9$ \\
\hline Age (years; average \pm sd) & $9.4 \pm 3.7$ & $9.5 \pm 4.5$ & $6.9 \pm 4.3$ & $5.4 \pm 4.2$ \\
\hline Breeds (n) & 39 & 4 & 29 & 2 \\
\hline \multirow[t]{3}{*}{ More prevalent breeds (\%) } & $\begin{array}{l}\text { Mongrel } \\
(23.9)\end{array}$ & Mongrel (82.7) & $\begin{array}{l}\text { Mongrel } \\
(50.0)\end{array}$ & Mongrel (96.6) \\
\hline & $\begin{array}{l}\text { Poodle } \\
\text { (16.5) }\end{array}$ & Siamese (11.1) & $\begin{array}{l}\text { Poodle } \\
(4.9)\end{array}$ & $\begin{array}{l}\text { Persian } \\
(3.4)\end{array}$ \\
\hline & Labrador (10.3) & $\begin{array}{l}\text { Persian } \\
(4.9)\end{array}$ & Dachshund (4.5) & - \\
\hline
\end{tabular}


Table 2 The degree of agreement and comparison between underestimation, agreement, and overestimation proportions of BCS attributed by dog and cat owners in the metropolitan region and countryside region considering all animals and separated by BCS range

\begin{tabular}{|c|c|c|c|c|c|c|}
\hline & \multicolumn{2}{|l|}{ All regions } & \multicolumn{2}{|c|}{ Metropolitan region } & \multicolumn{2}{|c|}{ Countryside region } \\
\hline & Dogs & Cats & Dogs & Cats & Dogs & Cats \\
\hline \multicolumn{7}{|c|}{ ALL BODY CONDITIONS SCORES (BCS 1 to 9) } \\
\hline $\mathrm{n}$ & 601 & 110 & 377 & 81 & 224 & 29 \\
\hline Underestimation & $44.8 \%$ & $50.0 \%$ & $35.0 \%$ & $43.2 \%$ & $61.2 \%$ & $69.0 \%$ \\
\hline Agreement & $38.8 \%$ & $40.9 \%$ & $44.0 \%$ & $44.4 \%$ & $29.9 \%$ & $31.0 \%$ \\
\hline Overestimation & $16.5 \%$ & $9.1 \%$ & $21.0 \%$ & $12.4 \%$ & $8.9 \%$ & $0.0 \%$ \\
\hline Kappa & 0.64 & 0.69 & 0.69 & 0.69 & 0.54 & 0.58 \\
\hline$p^{*}$ & $<0.01$ & $<0.01$ & $<0.01$ & $<0.01$ & $<0.01$ & $<0.01$ \\
\hline Degree of agreement & High & High & High & High & Moderate & Moderate \\
\hline \multicolumn{7}{|l|}{ LEAN (BCS 1 to 3) } \\
\hline$n$ & 89 (14.8\%) & 39 (35.5\%) & $62(16.4 \%)$ & $37(45.7 \%)$ & $27(12.1 \%)$ & $2(6.9 \%)$ \\
\hline n (BCSO) & $100(16.6 \%)$ & 49 (44.5\%) & $67(17.8 \%)$ & 45 (55.4\%) & $33(14.7 \%)$ & $4(13.9 \%)$ \\
\hline Underestimation & $16.9 \%$ & $25.6 \%$ & $19.4 \%$ & $27.0 \%$ & $11.1 \%$ & $0.0 \%$ \\
\hline Agreement & $47.2 \%$ & $56.4 \%$ & $43.6 \%$ & $54.1 \%$ & $55.6 \%$ & $100.0 \%$ \\
\hline Overestimation & $36.0 \%$ & $17.9 \%$ & $37.1 \%$ & $18.9 \%$ & $33.3 \%$ & $0.0 \%$ \\
\hline Kappa & 0.34 & 0.45 & 0.31 & 0.42 & 0.42 & - \\
\hline $\mathrm{p}^{*}$ & $<0.01$ & $<0.01$ & $<0.01$ & $<0.01$ & $<0.01$ & - \\
\hline Degree of agreement & Reasonable & Moderate & Reasonable & Moderate & Moderate & - \\
\hline \multicolumn{7}{|l|}{ IDEAL (BCS 4 and 5) } \\
\hline$n$ & $149(24.8 \%)$ & 26 23.6\%) & $90(23.9 \%)$ & 19 (23.5\%) & 59 (26.3\%) & $7(24.1 \%)$ \\
\hline n (BCSo) & $177(29.5 \%)$ & $28(25.5 \%)$ & $90(23.9 \%)$ & $16(19.8 \%)$ & 87 (38.8\%) & $12(41.7 \%)$ \\
\hline Underestimation & $37.6 \%$ & $57.7 \%$ & $27.8 \%$ & $63.2 \%$ & $52.5 \%$ & $42.9 \%$ \\
\hline Agreement & $40.3 \%$ & $34.6 \%$ & $44.4 \%$ & $26.3 \%$ & $33.9 \%$ & $57.1 \%$ \\
\hline Overestimation & $22.2 \%$ & $7.7 \%$ & $27.8 \%$ & $10.5 \%$ & $13.6 \%$ & $0.0 \%$ \\
\hline Kappa & 0.20 & 0.10 & 0.24 & 0.03 & 0.11 & 0.36 \\
\hline$p^{*}$ & $<0.01$ & 0.19 & $<0.01$ & 0.72 & 0.11 & 0.15 \\
\hline Degree of agreement & Low & - & Reasonable & - & - & - \\
\hline \multicolumn{7}{|c|}{ OVERWEIGHT (BCS 6 and 7) } \\
\hline $\mathrm{n}$ & $182(30.3 \%)$ & $17(15.5 \%)$ & $108(28.6 \%)$ & $8(9.9 \%)$ & $74(33.0 \%)$ & $9(33.3 \%)$ \\
\hline n (BCSO) & $225(37.4 \%)$ & $18(16.4 \%)$ & 139 (36.9\%) & $9(11.1 \%)$ & $86(38.4 \%)$ & $9(33.3 \%)$ \\
\hline Underestimation & $46.2 \%$ & $70.6 \%$ & $31.5 \%$ & $50.0 \%$ & $67.6 \%$ & $88.9 \%$ \\
\hline Agreement & $39.0 \%$ & $23.5 \%$ & $46.3 \%$ & $37.5 \%$ & $28.4 \%$ & $11.1 \%$ \\
\hline Overestimation & $14.8 \%$ & $5.9 \%$ & $22.2 \%$ & $12.5 \%$ & $4.1 \%$ & $0.0 \%$ \\
\hline Kappa & 0.18 & 0.13 & 0.20 & 0.11 & 0.10 & 0.07 \\
\hline$p^{*}$ & $<0.01$ & 0.05 & $<0.01$ & 0.29 & 0.01 & 0.27 \\
\hline Degree of agreement & Low & - & Low & - & Low & - \\
\hline \multicolumn{7}{|l|}{ OBESE (BCS 8 and 9) } \\
\hline$n$ & $181(30.1 \%)$ & $28(25.5 \%)$ & $117(31.0 \%)$ & 17 (21.0\%) & $64(28.6 \%)$ & $11(37.9 \%)$ \\
\hline n (BCSO) & 99 (16.5\%) & $15(13.6 \%)$ & $81(21.5 \%)$ & $11(13.6 \%)$ & $18(8.0 \%)$ & $4(11.1 \%)$ \\
\hline Underestimation & $63.0 \%$ & $64.3 \%$ & $51.1 \%$ & $52.9 \%$ & $82.8 \%$ & $81.8 \%$ \\
\hline Agreement & $33.2 \%$ & $35.7 \%$ & $41.9 \%$ & $47.1 \%$ & $17.2 \%$ & $18.2 \%$ \\
\hline Overestimation & $3.9 \%$ & $0.0 \%$ & $6.0 \%$ & $0.0 \%$ & $0.0 \%$ & $0.0 \%$ \\
\hline Kappa & 0.14 & 0.17 & 0.18 & 0.18 & 0.07 & 0.10 \\
\hline
\end{tabular}


Table 2 The degree of agreement and comparison between underestimation, agreement, and overestimation proportions of BCS attributed by dog and cat owners in the metropolitan region and countryside region considering all animals and separated by BCS range (Continued)

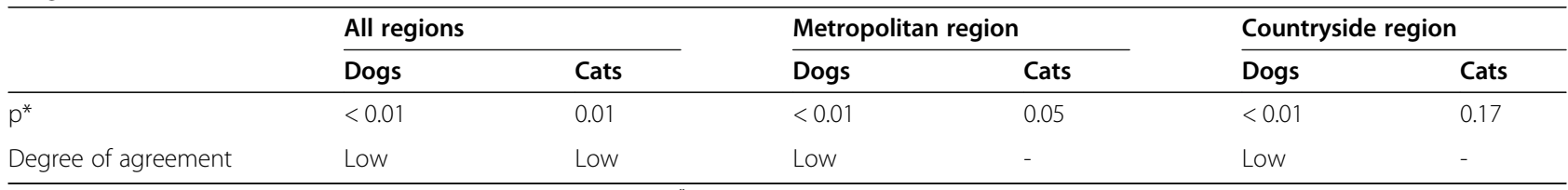

$n$ number of animals; BCSo body condition score classified by owners; ${ }^{*}$ Assessment of the degree of agreement between the BCS assigned by the owner and the veterinarian according to Kappa Weighted Test. The result was considered significant when $p<0.05$

(73.1\% vs. $26.9 \% ; p<0.01)$ and cats $(84.6 \%$ vs. $15.4 \% ; p<$ $0.01)$ owners, who disagreed with $\mathrm{BCSv}$, more frequently underestimate the $\mathrm{BCS}$ of their animals than overestimate it (Figs. 1 and 2).

Furthermore, comparing dogs vs. cats owners, there was no difference in the proportions of underestimation, agreement, or overestimation $(p>0.05)$. Among the regions, it was possible to notice that the owners from the metropolitan region are more likely to agree with the veterinarian compared to the countryside region $(44.0 \%$ vs. $29.9 \% ; p<0.01)$, they are unlikely to underestimate ( $35.0 \%$ vs. $61.2 \% ; p<0.01)$ and likely to overestimate the body condition of their dogs $(21.0 \%$ vs. $8.9 \%$; $p<0.01)$. Whereas, metropolitan cats owners had a lower underestimate ratio of the BCS compared to the residents of countryside region ( $43.2 \%$ vs. $69.0 \% ; p=0.03)$, without different $(p>0.05)$ for agreement and overestimation.

However, when these results are analyzed by the BCS group, the degree of agreement varied from low to moderate: for lean dogs, the agreement was reasonable in the metropolitan area $(\kappa=0.31 ; p<0.01)$ and moderate in the countryside $(\kappa=0.42 ; p<0.01)$; dogs with ideal BCS, the agreement was reasonable in the metropolitan area $(\kappa=0.24 ; p<0.01)$ and without significance to demonstrate the degree of agreement in the countryside ( $p=$ 0.11 ); and for both overweight and obese dogs the agreement was low regardless of the region $(\kappa=0.07$ to 0.18 ; $p<00.01)$.

For cats, when the total number of animals per BCS group was analyzed, it was possible to state that the degree of agreement was moderate for lean animals $(\kappa=0.45 ; p<0.01)$ and low for obese animals ( $\mathrm{K}=$ $0.17 ; p=0.01)$. Among the owners of the metropolitan region the degree of agreement was moderate $(\kappa=0.42 ; p<0.01)$ between BCSo and BCSv in the group of lean cats. For the remaining BCS groups, the degree of agreement could not be determined due to non-significance in the linear weighted kappa test $(p>0.05)$, probably due to the low number of cats in the present study.

When BCS perception among dog and cat owners was compared, there was only a difference in the group of

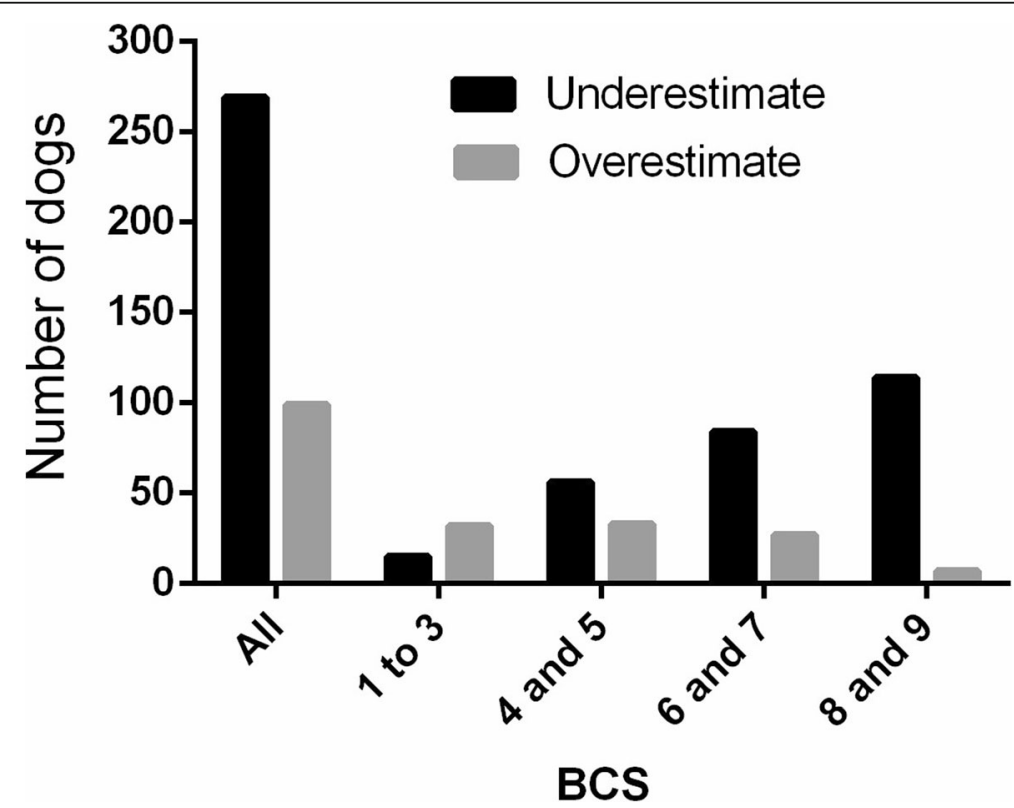

Fig. 1 Evaluation of the propensity of the owners, who disagreed with the veterinarian, in underestimating or overestimating the body condition score (BCS) of dogs 


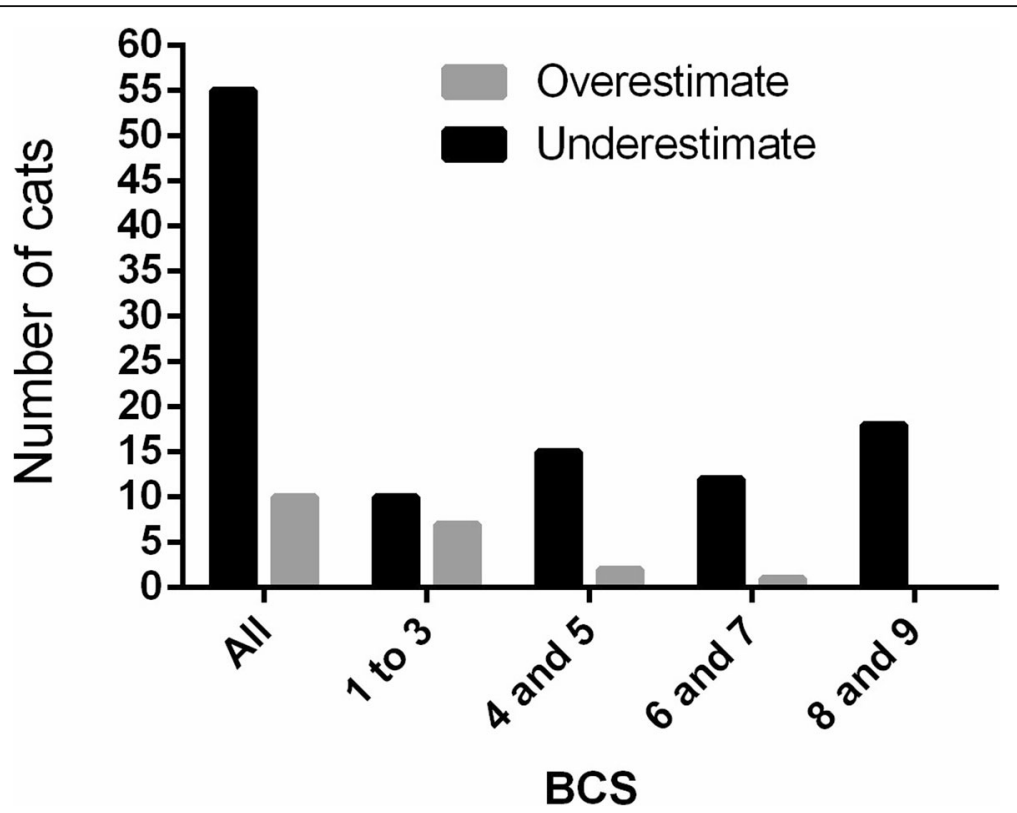

Fig. 2 Evaluation of the propensity of the owners, who disagreed with the veterinarian, in underestimating or overestimating the body condition score (BCS) of cats

animals with ideal BCS in the metropolitan region $(p<$ 0.01 ), in which cats owners seem to more frequently underestimate the BCS of their animal than dogs owners (63.2 vs. $27.8 \%)$.

Between the metropolitan region and countryside region, when the data are analyzed separated by the BCS groups, there was no difference between the perception of cats owners in the proportion of underestimation, agreement, and overestimation $(\mathrm{p}>0.05)$. However, it was observed that dog owners in the countryside region had a higher ratio of underestimate the BCS of dogs in ideal condition $(52.5 \%$ vs. $27.8 \% ; p<0.01)$, overweight $(67.6 \%$ vs. $31.5 \% ; p<0.01)$ and obesity $(82.8 \%$ vs. $51.1 \%$; $p<0.01$ ); and had a lower agreement ratio with the veterinarian when dogs are overweight $(28.4 \%$ vs. $46.3 \%$; $p=0.02)$ and obese $(17.2 \%$ vs. $41.9 \%$; $p<0.01)$; and consequently had a lower overestimate level of the BCS of overweight dogs ( $4.1 \%$ vs. $22.2 \%$; $p<0.01)$.

When comparing underestimation and overestimation (Table 2), it was observed that the dogs owners that do not agree with the BCSv are likely to overestimation of the BCS of lean dogs $(68.1 \%$ vs. $31.9 \% ; \mathrm{p}<0.01)$, and underestimation of the BCS of dogs in ideal condition $(62.9 \%$ vs. $37.1 \% ; p<0.01)$, overweight $(75.7 \%$ vs. $24.3 \% ; p<0,01)$ and obese $(94.2 \%$ vs. $5.8 \% ; p<0.01)$. There is also a greater susceptibility to underestimation of BCS among owners of obese felines $(100.0 \%$ vs. $0.0 \% ; p<0.01)$, overweight $(92.3 \%$ vs. $1.7 \% ; p<0.01)$ and ideal condition $(88.2 \%$ vs. $11.8 \% ; p<0.01)$. Furthermore, among the lean cats there was no difference in the proportion of underestimation and overestimation (58.8\% vs. $41.2 \%$; $p=0.49$ ).

\section{Discussion}

Considering the subjectivity of the BCS used [28, 29] and the low frequency of use of this method by veterinarians [41], the study was conducted by the veterinary clinical nutrition team. These veterinarians have extensive experience in the evaluation of the body condition of dogs and cats, which allowed BCSv to be used as a gold standard since this method has a good correlation with more objective alternatives such as dual-energy $\mathrm{x}$ ray absorptiometry for establishing the body composition when executed by experienced professionals [42]. Although it has been shown that the use of pictures does not improve the perception of the dog owners regarding the actual body condition of their animals [31, 32, 35], this study chose to use an illustrative chart of the BCS of dogs and cats, with a nine-point scale, to explain to the owners each body condition point, since its use seems to be a modifying factor of BCS attribution by cat owners [40] and the dog owners consider that the pictures help in the assignment of BCS [31]. The results observed in the present study show that Brazilian pet owners have difficulty in assessing the body condition of their animals, $61.2 \%$ of dog owners and $59.1 \%$ of cat owners disagree with BCSv. These results are close to those observed in the literature, where it was previously reported a range of $44.1-72 \%$ in the proportion of disagreement by dog owners [31-33, 35] and $47.3 \%$ disagreement by cats owners [40]. 
Moreover, there was a similarity between the previous studies and the present study in the distribution of the disagreement between $\mathrm{BCSv}$ and BCSo. In this study, as in other publications $[30,31]$, the owners of lean dogs, when in disagreement with the veterinarian, overestimated the animal's body condition, and owners of overweight and obese dogs underestimate the BCS. The fact that the dog owners classify the leans animals as being in healthier body condition was also observed by White et al. [33] and was associated with the owner's optimism in seeing their animals recovering from some illness that led to weight loss. Furthermore, a similar result was found in a past study with cat owners [40], the owners of lean cats who disagree with the veterinarian, overestimated the BCS of their animal, while those in ideal condition, overweight, and obese underestimated it. The difference in the present study is that there was no difference between underestimation and overestimation among the owners of leans animals that disagreed with BCSv.

Specifically regarding the group of obese animals, in both species, there was an underestimation of the body condition by the majority of the owners, to the point that the dogs linearized kappa values decreased as the BCS increased, which resulted in a low degree of agreement in the dogs. Additionally, in the present study, $30.1 \%$ of the dogs and $25.5 \%$ of the cats were diagnosed with obesity by the veterinarians $(B C S \geq 8)$, while only $16.5 \%$ and $13.6 \%$ (respectively) of the owners agreed with the BCSv. Likewise, Singh et al. [32] reported that 79\% of the dogs were racked as overweight by the veterinarians, whereas only $28 \%$ of the dogs were scored in this condition by the owners. A Brazilian study published by Aptekmann et al. [34], with a focus on overweight dogs, reported $52 \%$ of dogs with $\mathrm{BCS} \geq 8$, however, only $27 \%$ were obese in the owner's opinion. Likewise, in another study conducted in Brazil by Carciofi et al. [35], selected only obese dogs, $52 \%$ of owners underestimated the BCS of their animals.

This distinction between the regions in the state of São Paulo may be explained by the theory that people in large urban centers treat their animals like family and consequently are more concerned with pet health. However, this study did not consider the characteristics of the owners as their body condition, educational level, social class, type of interaction with pets etc., factors that could interfere in the way they perceive the BCS of their dogs, as observed by Courcier et al. [30] and that would be interesting parameters to be used as predisposing to owners who erroneously perceive the animal's body condition [44] This shows that the results of this study should be analyzed with thoughtfulness, as they probably do not reflect the reality of the perception of the entire
Brazilian population regarding the body condition of their animals.

With the humanization of pets, pet owner behaves like parents of children, and do not perceive the degree of obesity of the children $[45,46]$. Just as in human medicine, in what efforts are made for humans to recognize the body condition of their children and their own, in veterinary medicine to know how the owners see the BCS of their animals is fundamental for new interventions to be established prevention and treatment of obesity and other nutritional disorders. Owners that view their animals as in lower BCS than they are is harmful because, some owners may try to increase their pet's weight in pursuit of what they believe to be the proper body condition, and make it difficult for the veterinarian to establish a weight loss program. Likewise, the propensity to see their animal in an ideal body condition when the animal is lean can be a problem, making it difficult to establish intensive nutritional support to pets that do not ingest the adequate amount of nutrients and energy and the owners may not accept the veterinary intervention.

The nutritional assessment guide developed and endorsed by various veterinary entities recommends that the owners be educated by the veterinarian to recognize the differences between the BCS points [47, 48] since the success in the treatment of obesity is linked to the adherence of the owners to veterinary prescriptions, which depends on the awareness of that their animal is above [14] or below the ideal body condition and this can be harmful to the health of their animal $[8,49]$. Thus, research with this focus on veterinary medicine should be encouraged. This study evidences the discrepancy between owners and veterinarians regarding the body condition of their animal. The consistency between the BCS of a veterinarian and the owners is a key factor for the success of a weight loss program and the implementation of intensive nutritional support.

Some research has already evaluated the perception of dogs and cats owners regarding the body condition of their pets. However, the innovative character of this study is the fact that data were established in Brazilian territory, different from the studies that developed their work with dogs in the United Kingdom [30, 31, 33] and cats in France [40] or worked in Brazil only with dogs in overweight and obese [34]. Furthermore, to the best of our knowledge, this is the first study that compared the perception of BCS by dogs and cats owners and found a difference in the perception between the owners of both species only when the data were analyzed separately by the cities and by BCS groups: dogs that lived in the metropolitan area in ideal body condition had the BCS more frequently underestimated by their owners than the cats that lived in the same area $(63.2 \%$ vs. $27.8 \%, p=$ 
0.01). This could be attributed to the fact that dogs owners who exercise with their pets could consider physical activity as an influencing factor and thus underestimate the weight of the animal, however, this study was not focused on this hypothesis and therefore this study was not designed to confirm this hypothesis in the present study.

Another limitation of this study was the lower number of owners of cats when compared to the number of owners of dogs and the possibility of biases by the type of convenience sampling: the owners interviewed were those attended by the veterinary clinical nutrition team, which may have generated some degree of improvement in the perception of their pet's body condition because they have previously talked to other veterinarians about the weight of their animals. As stated by White et al. [33], a greater degree of agreement between the body condition scored by the veterinarian and by the owners is associated with a high percentage (75\%) of owners having already discussed with their veterinarian about their dog's weight. It is important to highlight that we did not have inclusion criteria for participation in the study since we had more overweight and obese dogs than cats for nutritional evaluation.

The present study has also emphasized the need to educate the public regarding companion animal obesity. In this respect, most of the owners interviewed had no prior knowledge of BCS and how to use it. This might be due to the fact that veterinarians do not commonly weigh dogs or estimate their body condition [42] therefore, they do not record the overweight status of pets [43]. Tackling owner misperception of body condition is arguably one way whereby veterinarians could improve owner awareness of a healthy weight and the importance to avoid obesity.

Moreover, the present study observed that the perception of dog owners is modified according to the region in which they reside: countryside owners see their dogs leaner than they really are and this may negatively impact the prevalence and treatment of pet obesity in these regions. As for the cat owners, this difference was not observed, but comparatively, French cat owners agree more with the veterinarian than Brazilian cat owners: $40.9 \%$ vs. $60 \%$ (Brazilian vs. French cat owners) [40].

\section{Conclusions}

The results obtained here was no significant difference in the perception of BCS by owners of dogs and cats. There is a need to educate the public regarding companion animal obesity and malnutrition, considering the differences between pet owners in the metropolitan areas and the countryside, in addition to using the BCS as a tool to improve communication between veterinarians and pet owners, to make the owners accept and adherence the nutritional interventions necessary for the treatment of the animal.

\section{Methods}

During the first appointment carried out by the veterinary clinical nutrition team between October 2013 and May 2018, all animals older than 1 year were enrolled in the study, regardless of diagnosis. Veterinarians explained to cat and dog owners how to assess the BCS using an illustration with a nine-point scale $[28,29]$ to exemplify the score. The illustrations chart translated into Brazilian Portuguese is made available in Brazil by the pet food company Nestlé Purina (Ribeirão Preto, SP, Brazil). The owners classified their animals BCS (BCSo) without interference from the veterinarian. The $\mathrm{BCS}$ assigned by the veterinarians (BCSv) was used as the standard to determine the degree of agreement between the BCSo and the accurate BCS. All veterinarians involved in this study were part of the same clinical nutrition team and underwent the same form of training prior to the BCS assessment. All animals remain with their owners during the appointment and returned to their homes after it.

Analyses were performed considering all data (regardless of the region where the appointments were held), the data from the metropolitan region (São Paulo city $11,253,503$ inhabitants and 7,387.96 inhabitants per $\mathrm{km}^{2}$ [50]) vs. the countryside region (Pirassununga city -70 , 081 inhabitants and a demographic density of 96.38 inhabitants $/ \mathrm{km}^{2}$ [50]) of São Paulo state, Brazil, and data from dogs and cats owners. BCS perceptions were evaluated using the nine-point scale [28, 29] or subdivided into four body condition groups: lean (1 to 3$)$, ideal (4 and 5), overweight (6 and 7), and obese (8 and 9).

The statistical analyses were performed in $\mathrm{R}$ Core Team software $(2016)^{2}$. The degree of concordance between BCSo and BCSv was assessed by the linear weighted Kappa (Kp) test that verifies if there is more agreement that would occur due to chance. According to the results of this test the degree of agreement is categorized as very low $(\kappa<0.00)$, low $(0.00$ to 0.20$)$, reasonable $(0.21$ to 0.40$)$, moderate $(0.41$ to 0.60$)$, high $(0.61$ to 0.80 ) and almost perfect ( 0.81 to 1.00$)$ [51]. A chi-square test of proportions equality was used to test if there was a difference between the perceptions of dog vs. cats owners, between owners from metropolitan vs. countryside areas of São Paulo state, and the likelihood of owners who disagreed with the BCSv is to underestimate or overestimate the BCS of their animal. For both tests, the results were considered significant when the $\mathrm{p}$-value was less than 0.05 .

\footnotetext{
${ }^{2} \mathrm{R}$ Core Team. R: A Language and Environment for Statistical Computing. R Foundation for StatisticalComputing. Vienna, Austria, 2016.
} 


\section{Acknowledgements}

We would like to thank the staff of the School of Veterinary Medicine and Animal Science for all their support.

\section{Authors' contributions}

FAT, MRQ, PMO, RFGO, MCE, CND, and MFR were responsible for planning the study, selecting and treating animals, conducting the analysis, writing, and editing the manuscript. MAB was responsible for planning study, coordination, and reviewing the manuscript. All authors read and approved the manuscript.

\section{Funding}

All authors disclosed any financial and personal relationships with other people or organizations that could inappropriately influence (bias) the work.

\section{Availability of data and materials}

The datasets used and analysed during the current study are available from the corresponding author on reasonable request.

\section{Ethics approval and consent to participate}

The present study was conducted with the approval of the Committee of Ethics in Animal Use of the School of Veterinary Medicine and Animal Science of the University of São Paulo, under protocol 9029151014, and all procedures were performed with the owners' consent.

\section{Consent for publication}

Not applicable.

\section{Competing interests}

All authors disclosed any financial and personal relationships with other people or organizations that could inappropriately influence (bias) the work.

\section{Author details}

${ }^{1}$ Department of Animal Nutrition and Production, School of Veterinary Medicine and Animal Science, University of São Paulo, Av. Duque de Caxias Norte, 255, Pirassununga, SP, São Paulo, Brazil. ${ }^{2}$ Department of Animal Sciences, University of Illinois at Urbana-Champaign , Illinois, Urbana, USA.

Received: 20 July 2020 Accepted: 13 November 2020

Published online: 27 November 2020

\section{References}

1. Santarossa A, Parr JM, Verbrugghe A. The importance of assessing body composition of dogs and cats and methods available for use in clinical practice. J Am Vet Med Assoc. 2017;251:521-9.

2. Burkholder WJ. Use of body condition scores in clinical assessment of the provision of optimal nutrition. J Am Vet Med Assoc. 2000;217:650-4.

3. Courcier EA, Mellor DJ, Pendlebury E, Evans C, Yam PS. An investigation into the epidemiology of feline obesity in Great Britain: results of a crosssectional study of 47 companion animal practises. Vet Rec. 2012;171:560

4. Usui S, Yasuda H, Koketsu Y. Characteristics of obese or overweight dogs visiting private Japanese veterinary clinics. Asian Pac J Trop Biomed. 2016;6: 338-43.

5. Brooks D, Churchill J, Fein K, Linder D, Michel KE, Tudor K, Ward E, Witzel A. 2014 AAHA weight management guidelines for dogs and cats. J Am Anim Hosp Assoc. 2014;50:1-11.

6. Brunetto MA, Sá FC, Nogueira SP, Gomes M, de OS, Pinarel AG, Jeremias JT, de Paula FJA, Carciofi AC. The intravenous glucose tolerance and postprandial glucose tests may present different responses in the evaluation of obese dogs. Br J Nutr. 2011;106(Suppl 1):194-7.

7. Chandler M, Cunningham S, Lund EMM, Khanna C, Naramore R, Patel A, Day MJJ. Obesity and Associated Comorbidities in People and Companion Animals: A One Health Perspective. J Comp Pathol. 2017;156:296-309.

8. Scarlett JM, Donoghue S. Associations between body condition and disease in cats. J Am Vet Med Assoc. 1998;212:1725-31.

9. Chandler ML. Impact of Obesity on Cardiopulmonary Disease. Vet Clin North Am Small Anim Pract. 2016;46:817-30.

10. Clark M, Hoenig M. Metabolic Effects of Obesity and Its Interaction with Endocrine Diseases. Vet Clin North Am Small Anim Pract. 2016;46:797-815.
11. German AJ, Holden SL, Wiseman-Orr ML, Reid J, Nolan AM, Biourge V, Morris PJ, Scott EM. Quality of life is reduced in obese dogs but improves after successful weight loss. Vet J. 2012;192:428-34.

12. German A, Ryan V, German A, Wood I, Trayhurn P. Obesity, its associated disorders and the role of inflammatory adipokines in companion animals. Vet J. 2010;185:4-9.

13. Huck JL, Biery DN, Lawler DF, Gregor TP, Runge JJ, Evans RH, Kealy RD, Smith GK. A longitudinal study of the influence of lifetime food restriction on development of osteoarthritis in the canine elbow. Vet Surg. 2009;38:192-8.

14. Kealy RD, Lawler DF, Ballam JM, Mantz SL, Biery DN, Greeley EH, Lust G, Segre M, Smith GK, Stowe HD. Effects of diet restriction on life span and age-related changes in dogs. J Am Vet Med Assoc. 2002;220:1315-20.

15. Marshall WG, Bockstahler BA, Hulse DA, Carmichael S. A review of osteoarthritis and obesity: Current understanding of the relationship and benefit of obesity treatment and prevention in the dog. Vet Comp Orthop Traumatol. 2009;22:339-45.

16. Michel KE. Nutritional management of body weight. In: Fascetti AJ, Delaney SJ, editors. Applied Veterinary Clinical Nutrition. lowa: Wiley-Blackwell; 2012. pp. 109-24.

17. Baez JL, Michel KE, Sorenmo K, Shofer FS. A prospective investigation of the prevalence and prognostic significance of weight loss and changes in body condition in feline cancer patients. J Feline Med Surg. 2007;9:411-7.

18. Castro MCNe, Vieira AB, Santos MCS, Gershony LC, Soares AMB, Ferreira AMR. Body condition score as an indicator of prognosis for cats with chronic renal disease. Ciência Rural. 2010;40:335-40.

19. Finn E, Freeman LM, Rush JE, Lee Y. The relationship between body weight, body condition, and survival in cats with heart failure. J Vet Intern Med. 2010;24:1369-74.

20. Parker VJ, Freeman LM. Association between Body Condition and Survival in Dogs with Acquired Chronic Kidney Disease. J Vet Intern Med. 2011;25: 1306-11.

21. Peterson ME, Castellano CA, Rishniw M. Evaluation of Body Weight, Body Condition, and Muscle Condition in Cats with Hyperthyroidism. J Vet Intern Med. 2016;30:1780-9.

22. Romano FR, Heinze CR, Barber LG, Mason JB, Freeman LM. Association between Body Condition Score and Cancer Prognosis in Dogs with Lymphoma and Osteosarcoma. J Vet Intern Med. 2016;30:1179-86.

23. Slupe $\mathrm{L}$, Freeman LM, Rush JE. Association of body weight and body condition with survival in dogs with heart failure. J Vet Intern Med. 2008;22:561-5.

24. Brunetto MA, Gomes MOS, Andre MR, Teshima E, Gonçalves KNV, Pereira GT, Ferraudo AS, Carciofi AC. Effects of nutritional support on hospital outcome in dogs and cats. J Vet Emerg Crit care. 2010;20:224-31.

25. Harris JP, Parnell NK, Griffith EH, Saker KE. Retrospective evaluation of the impact of early enteral nutrition on clinical outcomes in dogs with pancreatitis: 34 cases (2010-2013). J Vet Emerg Crit Care. 2017;27:425-33.

26. Liu DT, Brown DC, Silverstein DC. Early nutritional support is associated with decreased length of hospitalization in dogs with septic peritonitis: A retrospective study of 45 cases (2000-2009). J Vet Emerg Crit Care. 2012;22: 453-9.

27. Remillard RL, Darden DE, Michel KE, Marks SL, Buffington CA, Bunnell PR. An investigation of the relationship between caloric intake and outcome in hospitalized dogs. Vet Ther Res Appl Vet Med. 2001;2:301-10.

28. Laflamme DP. Development and Validation of a Body Condition Score System for Dogs. Canine Pract. 1997;22:10-5.

29. Laflamme D. Development and validation of a body condition score system for cats: A clinical tool. Feline Pract. 1997;25:13-7.

30. Courcier EA, Mellor DJ, Thomson RM, Yam PS. A cross sectional study of the prevalence and risk factors for owner misperception of canine body shape in first opinion practice in Glasgow. Prev Vet Med. 2011;102:66-74.

31. Eastland-Jones RC, German AJ, Holden SL, Biourge V, Pickavance LC. Owner misperception of canine body condition persists despite use of a body condition score chart. J Nutr Sci. 2014;3:e45.

32. Singh R, Laflamme DP, Sidebottom-Nielsen M. Owner perceptions of canine body condition score. In: 20th Anual ACVIM Forum. Dallas: American College of Veterinary Internal Medicine; 2002. p. 362.

33. White GA, Hobson-West P, Cobb K, Craigon J, Hammond R, Millar KM Canine obesity: Is there a difference between veterinarian and owner perception? J Small Anim Pract. 2011;52:622-6.

34. Aptekmann KP, Suhett WG, Junior AFM, Souza GB, Tristão APPA, Adams FK, Aoki CG, Juan R, Palacios G, Carciofi AC. Tinucci-costa, M. Nutritional and environment aspects of canine obesity. Ciência Rural. 2014;44:2039-44. 
35. Carciofi AC, Gonçalves KNV, Vasconcellos RS, Bazolli RS, Brunetto MA, Prada F. A weight loss protocol and owners participation in the treatment of canine obesity. Ciência Rural. 2005;35:1331-8.

36. Rowe E, Browne W, Casey R, Gruffydd-Jones T, Murray J. Risk factors identified for owner-reported feline obesity at around one year of age: Dry diet and indoor lifestyle. Prev Vet Med. 2015;121:273-81.

37. Peron L, Dvm G, Rahal SC, Castilho MS, Melchert A, Vassalo FG, et al. Owner's Perception for Detecting Feline Body Condition Based on Questionnaire and Scores. Top Companion Anim Med. 2016;31:122-4.

38. Courcier EA, O'Higgins R, Mellor DJ, Yam PS. Prevalence and risk factors for feline obesity in a first opinion practice in Glasgow, Scotland. J Feline Med Surg. 2010;12:746-53.

39. Cave NJ, Allan FJ, Schokkenbroek SL, Metekohy CAM, Pfeiffer DU. A crosssectional study to compare changes in the prevalence and risk factors for feline obesity between 1993 and 2007 in New Zealand. Prev Vet Med. 2012; 107:121-33.

40. Colliard L, Paragon B-M, Lemuet B, Bénet J-J, Blanchard G. Prevalence and risk factors of obesity in an urban population of healthy cats. J Feline Med Surg. 2009;11:135-40.

41. German AJ, Morgan LE. How often do veterinarians assess the bodyweight and body condition of dogs? Vet Rec. 2008;163:503-5.

42. German AJ, Holden SL, Moxham GL, Holmes KL, Hackett RM, Rawlings JM. A Simple, Reliable Tool for Owners to Assess the Body Condition of Their Dog or Cat. J Nutr. 2006;136:2031S-2033S.

43. Rolf NC, Noble PJM, German AJ. How often do primary care veterinarians record the overweight status of dogs? J Nutritional Science. 2013 doi: https://doi.org/10.1017/jns.2014.42.

44. German AJ, Holden SL, Serisier S, Queau Y, Biourge V. Assessing the adequacy of essential nutrient intake in obese dogs undergoing energy restriction for weight loss: a cohort study. BMC Vet Res. 2015;11:253.

45. Black JA, Park MH, Gregson J, Falconer CL, White B, Kessel AS, Saxena S, Viner RM, Kinra S. Child obesity cut-offs as derived from parental perceptions: Cross-sectional questionnaire. Br J Gen Pr. 2015;65:e234-9.

46. Doolen J, Alpert PT, Miller SK. Parental disconnect between perceived and actual weight status of children: A metasynthesis of the current research. $J$ Am Acad Nurse Pr. 2009;21:160-6.

47. Baldwin K, Bartges J, Buffington T, Freeman LM, Grabow M, Legred J. Ostwald D. AAHA Nutritional Assessment Guidelines for Dogs and Cats. J Am Anim Hosp Assoc. 2010;46:285-96.

48. Freeman L, Becvarova I, Cave N, MacKay C, Nguyen P, Rama B, Takashima G, Tiffin R, van Beukelen P, Yathiraj S. WSAVA nutritional assessment guidelines. Feline Med Surg. 2011;13:516-25.

49. Doria-Rose VP, Scarlett JM. Mortality rates and causes of death among emaciated cats. J Am Vet Med Assoc. 2000;216:347-51.

50. Instituto Brasileiro de Geografia e Estatística Censo. 2010. Instituto Brasileiro de Geografia e Estatística. https://censo2010.ibge.gov.br/ (2010). Accessed 22 Sep 2020.

51. Landis JR, Koch GG. The measurement of observer agreement for categorical data. Biometrics. 1977;33:159-74.

\section{Publisher's Note}

Springer Nature remains neutral with regard to jurisdictional claims in published maps and institutional affiliations.

Ready to submit your research? Choose BMC and benefit from:

- fast, convenient online submission

- thorough peer review by experienced researchers in your field

- rapid publication on acceptance

- support for research data, including large and complex data types

- gold Open Access which fosters wider collaboration and increased citations

- maximum visibility for your research: over $100 \mathrm{M}$ website views per year

At $\mathrm{BMC}$, research is always in progress.

Learn more biomedcentral.com/submissions 